\title{
Macular hole retinal detachment after intravitreal Conbercept injection for the treatment of choroidal neovascularization secondary to degenerative myopia: a case report
}

\author{
Chuan-bin Sun ${ }^{1}$, Yueye Wang ${ }^{1}$, Shiyang Zhou', Xudong Fang ${ }^{1+}$, Danni $\mathrm{Xu}^{1+}$ and Zhe $\mathrm{Liu}^{2^{*}}$
}

\begin{abstract}
Background: We report a case of macular hole $(\mathrm{MH})$ formation and retinal detachment after intravitreal conbercept injection for the treatment of choroidal neovascularization (CNV) secondary to degenerative myopia.

Case presentation: A 60-year-old woman presented with blurred vision in her left eye was diagnosed as CNV secondary to degenerative myopia. Intravitreal injection of conbercept, an anti -vascular endothelial growth factor (VEGF) agent, was uneventfully performed in the left eye. Unfortunately, a full thickness MH and retinal detachment was found three weeks postoperatively by ophthalmoscopy and spectral-domain optical coherence tomography. Vitrectomy, internal limiting membrane peeling and silicone oil tamponade were then performed, and macular retina was reattached soon after surgery. However, MH still kept open during three months' follow-up.

Conclusion: $\mathrm{MH}$ is a quite rare complication of intravitreal anti- VEGF agent injection, tangential contraction secondary to CNV shrinkage and regression caused by anti-VEGF agent is proposed to be the major pathogenesis of $\mathrm{MH}$ formation.
\end{abstract}

Keywords: Choroidal neovascularization, Macular hole, Conbercept, Intravitreal injection, Degenerative myopia

\section{Background}

Choroidal neovascularization (CNV) is characteristic of many sight-threating fundus diseases such as exudative age-related macular degeneration (AMD), polypoidal choroidal vasculopathy, myopic $\mathrm{CNV}$, and idiopathic CNV [1-3]. Recently, intravitreal anti-vascular endothelial growth factor (VEGF) agents have successfully improved the treatment outcome and visual prognosis of $\mathrm{CNV}$. However, macular hole $(\mathrm{MH})$ formation has emerged to be a new challenging adverse effect of intravitreal anti-VEGF agent therapy for $\mathrm{CNV}$, which was mostly reported in anti-VEGF therapy for exudative AMD cases [3-13].

\footnotetext{
* Correspondence: doctorliuzhe@126.com

Dr. Fang $X D$ and $X u D N$ are trainees

${ }^{2}$ Department of Ophthalmology, Zhejiang Provincial People's Hospital,

People's Hospital of Hangzhou Medical College, Hangzhou 310015, China

Full list of author information is available at the end of the article
}

We herein present a case of $\mathrm{MH}$ formation and retinal detachment after intravitreal conbercept injection for the treatment of $\mathrm{CNV}$ caused by degenerative myopia.

\section{Case presentation}

A 60-year-old woman complained of blurred vision in her left eye for one week. On presentation, the best corrected visual acuity (BCVA) was 0.6 in the right eye, and hand motion in the left eye. Slit lamp examination revealed normal anterior segment in both eyes. Direct ophthalmoscopy revealed slight macular epiretinal membrane in the right eye, and grey submacular membrane surrounded by subretinal hemorrhage in the left eye (Fig. 1a). The axial length of the right eye was 30.61 $\mathrm{mm}$, and that of the left eye was $30.43 \mathrm{~mm}$ by IOL Master measurement. Fundus fluorescein angiography revealed early-staged submacular hyperfluorescence

(c) The Author(s). 2019 Open Access This article is distributed under the terms of the Creative Commons Attribution 4.0 International License (http//creativecommons.org/licenses/by/4.0/) which permits unrestricted use, distribution, and reproduction in any medium, provided you give appropriate credit to the original author(s) and the source, provide a link to the Creative Commons license, and indicate if changes were made. The Creative Commons Public Domain Dedication waiver (http://creativecommons.org/publicdomain/zero/1.0/) applies to the data made available in this article, unless otherwise stated. 


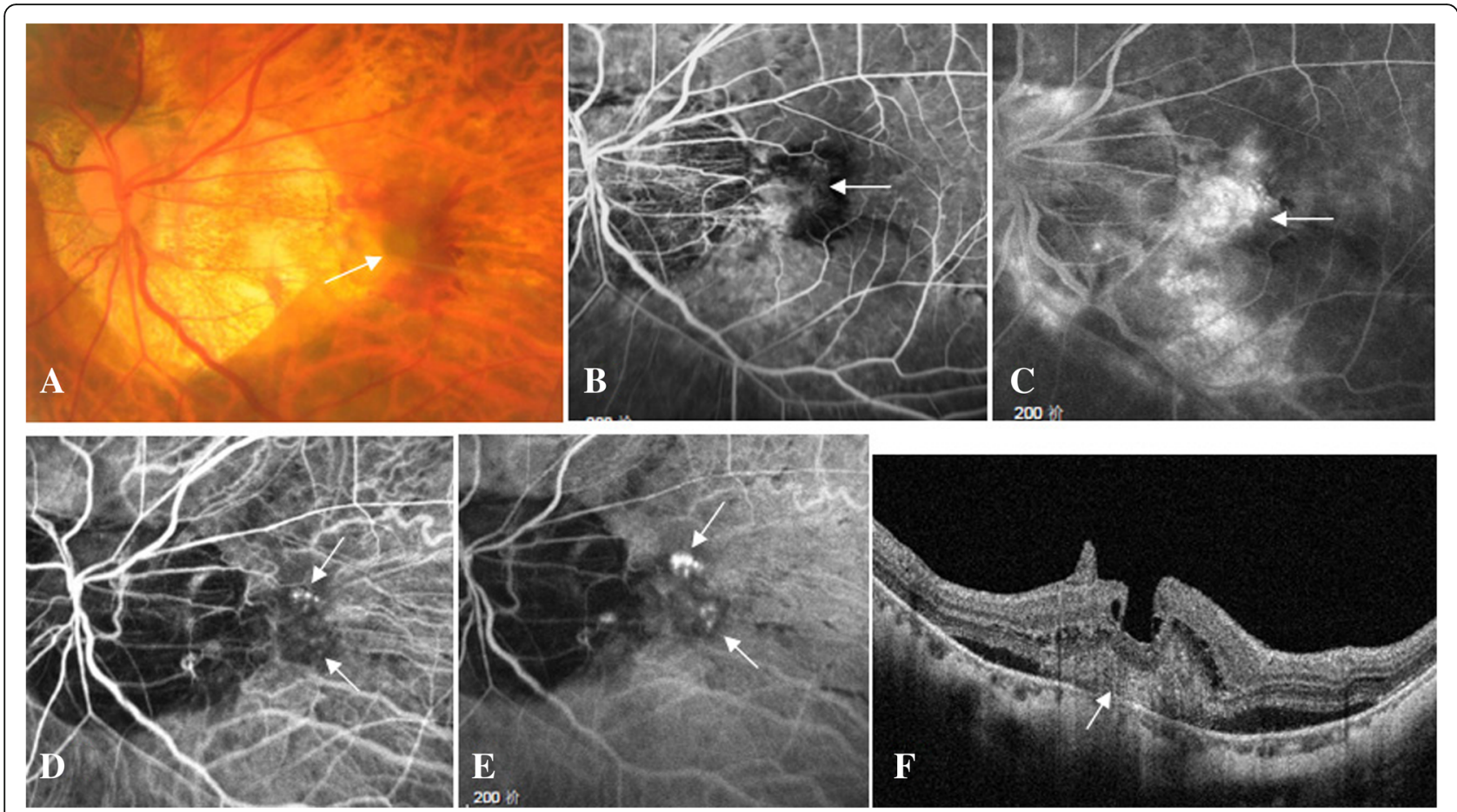

Fig. 1 Macular findings on presentation. A 60-year-old woman presented with a complaint of blurred vision in her left eye for one week. On presentation, the best corrected visual acuity (BCVA) of her left eye was hand motion, the axial length $30.43 \mathrm{~mm}$. Color fundus photograph showed grey submacular membrane (arrow) surrounded by subretinal hemorrhage (a). Fundus fluorescein angiography revealed early-staged submacular hyperfluorescence lesion (arrow, b), followed by strong fluorescein leakage and enlargement of hyperfluorescence in the late phase (arrow, c). Indocyanine green angiography demonstrated early-staged clustered hyperfluorescence spots (arrow, d), which showed evident leakage and enlargement in the late phase (arrow, e). Spectral-domain optical coherence tomography (SD-OCT) revealed type 2 CNV (arrow) surrounded by serous neurosensory macuar detachment and intraretinal cysts above CNV (f)

lesion (Fig. 1b), followed by strong fluorescein leakage and enlargement of hyperfluorescence in the later phases (Fig. 1c). Indocyanine green angiography demonstrated early-staged clustered hyperfluorescence spots (Fig. 1d), which showed evident leakage and enlargement in the later phases (Fig. 1e), confirming an active CNV in the left eye. Spectral-domain optical coherence tomography (SD-OCT) revealed type 2 $\mathrm{CNV}$ surrounded by serous neurosensory macuar detachment and intraretinal cysts above CNV in the left eye (Fig. 1f). Her past medical history was not remarkable. CNV secondary to degenerative myopia in the left eye was then diagnosed and uneventful intravitreal conbercept $(2.5 \mathrm{mg} / 0.05 \mathrm{ml})$ injection was performed soon after the informed consent was signed.

Three weeks after the injection, the patient came back with a complaint of central scotoma in the left eye. BCVA was counting fingers, funduscopic examination revealed a full thickness $\mathrm{MH}$ and surrounded retinal detachment (Fig. 2a), SD-OCT comfirmed a full thickness $\mathrm{MH}$ accompanied by macular detachment and intraretinal cysts in the left eye (Fig. 2b). Vitrectomy, internal limiting membrane peeling assisted by indocyanine green staining, and silicone oil tamponade were successfully performed in the left eye. Postoperative SDOCT at one week's follow-up revealed a reattached macular retina yet still open $\mathrm{MH}$ in the left eye. At three months' follow-up, BCVA in the left eye was 0.05, $\mathrm{MH}$ still kept open depite successful macular reattachment and Fuchs spot formation (Fig. 2c, d) which was characterized by a hyperreflective subretinal spot in SD-OCT.

\section{Discussion and conclusions}

$\mathrm{MH}$ is a rare yet sight threating complication of intravitreal anti-VEGF agent injection [3-13]. Our literature research based on Pubmed database revealed that there were only dozens of cases who developed a full thickness $\mathrm{MH}$ after intravitreal injection of anti-VEGF angents which were mostly involved with ranibizumab and bevacizumab, and occasionally with aflibercept [3-15]. To our knowledge, this is the first case report of $\mathrm{MH}$ formation after intravitreal conbercept injection.

Our report about conbercept-induced MH formation, together with previous case reports of other anti-VEGF agents (such as ranibizumab, bevacizumab, and aflibercept) induced $\mathrm{MH}$ formation, provides an important insight into the pathogenesis of $\mathrm{MH}$ formation after anti-VEGF therapy in eyes with $\mathrm{CNV}$, and reveals that $\mathrm{MH}$ formation would 

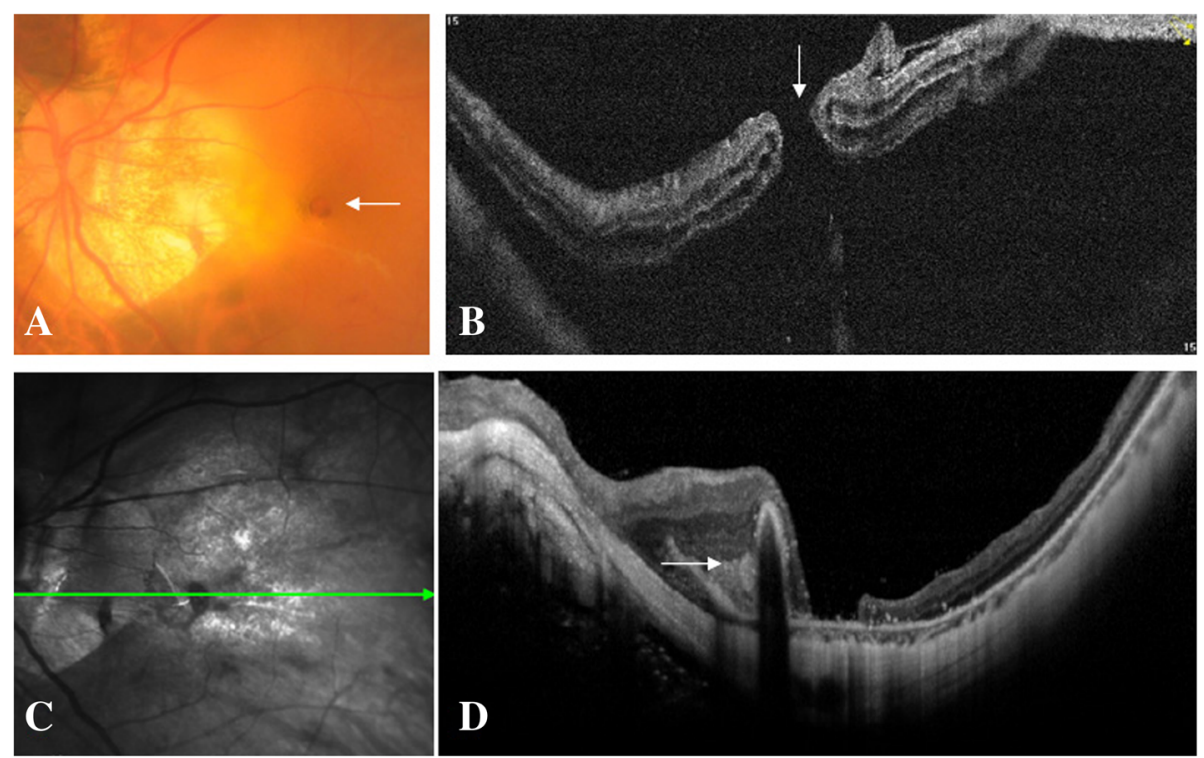

Fig. 2 Macular hole formation after intravitreal conbercept injection. Three weeks after the injection, BCVA was counting fingers in the left eye, color fundus photograph revealed a full thickness macular hole $(\mathrm{MH})$ and surrounded retinal detachment (arrow, a). SD-OCT comfirmed a full thickness MH (arrow) accompanied by macular detachment and intraretinal cysts in the left eye (b). Three months after the vitrectomy and silicone oil tamponade, BCVA was 0.05 , color fundus photograph demonstrated that $\mathrm{MH}$ still kept open despite successful macular reattachment and Fuchs spot formation which was characterized by a hyperreflective subretinal spot in SD-OCT (arrow, c, d)

be caused by anti-VEGF effect rather than the other characteristics of anti-VEGF agents such as molecular weight, $\mathrm{pH}$, and three- dimensional structure. This finding is of great importance in helping $\mathrm{CNV}$ patients to choose an appropriate anti-VEGF agent.

The exact pathogenesis of $\mathrm{MH}$ formation after intravitreal injection of anti-VEGF angents is still under discussion. Shrinkage and regression of CNV induced by antiVEGF agents could cause centrifugal tangential contraction, this contraction probably led to tractional forces to foveal neural retina, and finally developed a full thickness $\mathrm{MH}[4,5,11-15]$. In this case, CNV tissue was positioned centrally beneath fovea before intravitreal conbercept injection, yet the regressed CNV tissue (Fuchs spot) was located at one edge of the MH after conbercept injection, which implied that the tangential contraction caused by the shrinked $\mathrm{CNV}$ might be the main mechanism of $\mathrm{MH}$ formation in $\mathrm{CNV}$ cases with intravitreal anti-VEGF agent injection. Many previous literature reports showed similar findings which strongly supported our speculation $[4,5,11-15]$.

Although $\mathrm{MH}$ formation after intravitreal anti-VEGF agent injection is quite rare, it should be kept in mind that such complication might occur after intravitreal injection of any anti-VEGF agent. CNV Patients should be warned about this potential complication, and it should also be included in the differential diagnosis when $\mathrm{CNV}$ lesions did not show any therapic response to or even deteriorated after anti-VEGF agent therapy $[4,5,13,15]$.
In conclusion, $\mathrm{MH}$ is a quite rare complication of intravitreal anti-VEGF agent injection, tangential contraction secondary to CNV shrinkage and regression caused by anti-VEGF agent is proposed to be the major pathogenesis of $\mathrm{MH}$ formation.

\section{Abbreviations \\ AMD: Age-related macular degeneration; BCVA: Best corrected visual acuity; CNV: Choroidal neovascularization; MH: Macular hole; SD-OCT: Spectral- domain optical coherence tomography; VEGF: Vascular endothelial growth facto}

\section{Acknowledgments}

The authors would like to acknowledge the funding support of the Administrative Bureau of Traditional Chinese Medicine of Zhejiang Province (No. 2015ZA055).

\section{Authors' contributions}

SC and LZ wrote and reviewed the manuscript; WY, ZS and XD collected, analyzed and interpreted the patient data; SC and FX performed medical treatment. All authors read and approved the final manuscript.

\section{Funding}

This study was supported in part by the Administrative Bureau of Traditional Chinese Medicine of Zhejiang Province (No. 2015ZA055). The funding organizations does not have any role in the design or conduct of this study.

\section{Availability of data and materials}

All data generated or analysed during this study are included in this published article.

\section{Ethics approval and consent to participate}

Institutional review board approvals were obtained from both Second Affiliated Hospital of Zhejiang University School of Medicine and Zhejiang Provincial People's Hospital. This study was conducted according to the 
tenets of the Declaration of Helsinki. Informed consents were obtained from all participants.

\section{Consent for publication}

Written informed consent was obtained from the patient for publication of this case report and any accompanying images. A copy of the written consent is available for review by the editor of this journal.

\section{Competing interests}

The authors declare that they have no competing interests.

\section{Author details}

${ }^{1}$ Eye Center, Second Affiliated Hospital of Zhejiang University School of Medicine, Hangzhou 310009, China. ²Department of Ophthalmology,

Zhejiang Provincial People's Hospital, People's Hospital of Hangzhou Medical College, Hangzhou 310015, China.

Received: 1 May 2019 Accepted: 12 July 2019

Published online: 22 July 2019

\section{References}

1. Solomon SD, Lindsley K, Vedula SS, Krzystolik MG, Hawkins BS. Anti-vascular endothelial growth factor for neovascular age-related macular degeneration. Cochrane Database Syst Rev. 2019;3:CD005139. https://doi. org/10.1002/14651858.CD005139.pub4 Review.

2. Ohno-Matsui K, Ikuno Y, Lai TYY. Gemmy Cheung CM. Diagnosis and treatment guideline for myopic choroidal neovascularization due to pathologic myopia. Prog Retin Eye Res. 2018;63:92-106.

3. Cho JH, Park SE, Han JR, Kim HK, Nam WH. Macular hole after intravitreal ranibizumab injection for polypoidal choroidal vasculopathy. Clin Exp Optom. 2011;94(6):586-8.

4. Oshima Y, Apte RS, Nakao S, Yoshida S, Ishibashi T. Full thickness macular hole case after intravitreal aflibercept treatment. BMC Ophthalmol. 2015;15:30.

5. Chan EW, Sun V, Chen JC. Reopening of macular hole after intravitreal aflibercept for neovascular age-related macular degeneration. Retin Cases Brief Rep. 2017. https://doi.org/10.1097//CB.0000000000000688.

6. Shif OA, Katz MSJ. Surgical management of full-thickness macular hole superimposed exudative age-related macular degeneration. Retin Cases Brief Rep. 2018, https://doi.org/10.1097/ICB.0000000000000786.

7. Mukherjee C, Mitra A, Kumar NA, Elsherbiny S, Lip PL. Macular hole formation after intravitreal ranibizumab injection in wet age-related macular degeneration. Open Ophthalmol J. 2015;9:177-80.

8. Tufan HA, Gencer B, Kara S. Macular hole after intravitreal bevacizumab injection for choroidal neovascularisation. Clin Exp Optom. 2014:97(2):178-80.

9. Moisseiev E, Goldstein M, Loewenstein A, Moisseiev J. Macular hole following intravitreal bevacizumab injection in choroidal neovascularization caused by age-related macular degeneration. Case Rep Ophthalmol. 2010;1(1):36-41.

10. Miura M, Iwasaki T, Goto H. Macular hole formation after intravitreal bevacizumab administration in a patient with myopic choroidal neovascularization. Retin Cases Brief Rep. 2011:5(2):149-52.

11. Rishi $P$, Kasinathan N, Sahu C. Foveal atrophy and macular hole formation following intravitreal ranibizumab with/without photodynamic therapy for choroidal neovascularization secondary to age-related macular degeneration. Clin Ophthalmol. 2011;5:167-70.

12. Hirata A, Hayashi K, Murata K, Nakamura Kl. Removal of choroidal neovascular membrane in a case of macular hole after anti-VEGF therapy for age-related macular degeneration. Am J Ophthalmol Case Rep. 2017:9:14-7

13. Regatieri CV, Duker JS. Bilateral macular hole after anti-vascular endothelia growth factor therapy in a patient with exudative age-related macular degeneration. Retin Cases Brief Rep. 2012;6(1):125-8.

14. Shimada N, Ohno-Matsui K, Hayashi K, Yoshida T, Tokoro T, Mochizuki M. Macular detachment after successful intravitreal bevacizumab for myopic choroidal neovascularization. Jpn J Ophthalmol. 2011;55(4):378-82.

15. Otsuka K, Imai H, Shimoyama T, Nagai T, Honda S, Azumi A. Recurrence of macular hole retinal detachment after intravitreal ranibizumab injection for the treatment of choroidal neovascularization from the remaining macular hole edge. Case Rep Ophthalmol. 2012;3(3):424-7.

\section{Publisher's Note}

Springer Nature remains neutral with regard to jurisdictional claims in published maps and institutional affiliations.

\section{Ready to submit your research? Choose BMC and benefit from:}

- fast, convenient online submission

- thorough peer review by experienced researchers in your field

- rapid publication on acceptance

- support for research data, including large and complex data types

- gold Open Access which fosters wider collaboration and increased citations

- maximum visibility for your research: over $100 \mathrm{M}$ website views per year

At $\mathrm{BMC}$, research is always in progress.

Learn more biomedcentral.com/submissions 